\title{
A LIGHTWEIGHT NUMERICAL MODEL OF RAILWAY TRACK TO PREDICT MECHANICAL STRESS STATE IN THE RAIL
}

\author{
MARYAM EL MOUEDDEB ${ }^{1,2}$, FRANÇOIS LOUF ${ }^{1}$, PIERRE-ALAIN BOUCARD $^{1}$, FRANCK DADIÉ $^{2}$, GILLES \\ SAUSSINE $^{2}$, DANILO SORRENTINO ${ }^{2}$ \\ ${ }^{1}$ LMT (ENS Paris-Saclay/CNRS/Université Paris-Saclay), France \\ ${ }^{2}$ SNCF Réseau, France
}

\begin{abstract}
A new approach is conducted within SNCF Réseau to redefine and improve the current procedure behind rolling stocks admission. A perspective to update computation rules for traffic conditions is to consider track fatigue issues. In this sense, the study aims to provide a better knowledge of stress state induced by moving vehicles in rails through a lightweight numerical model of the track. Specifically, the track model consists of a two-layer discrete support model in which the rail is considered as a beam and sleepers are punctual masses. The rail-pads and ballast layer are modelled as spring/damper couples. Considering the track's vertical response, the study intends to quantify the impact of the vehicle's dynamic overload on the track response and verify the possibility of these overloads to excite track vibration modes. A first study considering constant moving loads already shows negligible effect of track inertia forces due to high track stiffness and damping. This justifies the prediction of mechanical stress state in the rail for fatigue issues through a static model of the track and a simplified dynamic model for the vehicle.
\end{abstract}

Keywords: dynamic response, finite element method, moving load, simplified model, railway tracks

\section{INTRODUCTION}

The railway traffic management adopted by SNCF Réseau for classical lines is initially based on simplified analytical theories [1]. It has evolved though with feedbacks because of railway tracks and rolling stocks evolutions. Computation rules for traffic conditions allow to determinate the maximum speed $V_{\max }$ and the maximum cant deficiency $I_{\max }$ allowed for a vehicle regarding the vehicle's and track's properties [2]. A perspective to update these computation rules is to consider flexural rail fatigue issues. Indeed, classical lines in the French railway network can be loaded by either freight transport or passenger transport. Thus, the stress state in the same track is highly heterogeneous during its exploitation.

Numerical simulation in the railway field has become an efficient tool to predict a track's behaviour. As a matter of fact, several models have been developed. 3D finite element models of the track are proposed with a better representation of the track's foundation by implementing a settlement law of ballast layer as suggested in [3-5] and allowing non-linear constitutive laws of track's components [4-6]. Furthermore, some studies quantify geomaterials disparity and variability in track components characteristics with stochastic models [7,8]. Although accurate, 3D models remain very expensive and hardly suitable for industrial exploitations. Thus, the paper describes a finite element model of the track subjected to vertical vehicle's loading. Track inertia effects are investigated by comparing the dynamic track response to its equivalent static response. Then, dynamic overloads of the vehicle are applied to the track through a simplified multi-body vehicle model. The purpose is to predict the mechanical stress in the rail. 


\section{TRACK MODEL}

A lightweight finite element model of the track is developed using CAST3M software [9]. It illustrates a rail discretely supported by rail-pads and sleepers on a ballast layer. The rail is modelled as a beam and the sleepers are modelled as rigid punctual masses. Rail-pads and the ballast layer are represented by viscous dampers and linear springs (Fig. 1). The parameters used for the model are listed in Table 1.

In the present work, the track's behaviour is analysed over 19 sleeper bays (20 supports). In order to eliminate boundary effects, a buffer zone including 10 supports is added on both sides of the track. The buffer zone is chosen in such a way that reflected waves are attenuated over its length. Also, taking into consideration the symmetry of the track in its longitudinal direction, only half of the track is modelled (i.e. one rail).

Traffic conditions concern low frequencies in the range $[0 \mathrm{~Hz} ; 20 \mathrm{~Hz}]$ as security and stability issues are considered. Hence, the dynamic response of the track is studied in this frequency band. According to Knothe and Grassie [11], at low frequencies range [0Hz;20Hz], the track can be assumed as an infinitely rigid spring and its inertia is negligible in front of vehicle's inertia.

\section{VEHICLE'S DYNAMIC OVERLOADS CALCULATION}

In the frequency range of $[0 \mathrm{~Hz} ; 20 \mathrm{~Hz}]$, the track's inertia does not impact the vehicle's dynamic behaviour. Therefore, decoupling the vehicle's dynamic to the track's dynamic is justified, i.e. only track defects are the excitation source of the vehicle.

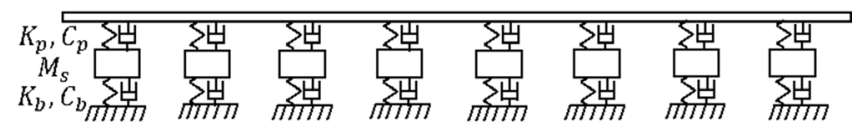

Figure 1: Lightweight finite element model of the track.

Table 1: Track parameters [10].

\begin{tabular}{lll}
\hline Rail & Density $\rho_{r}\left(\mathrm{~kg} / \mathrm{m}^{3}\right)$ & 7,850 \\
& Young Modulus $E(\mathrm{MPa})$ & 210,000 \\
& Cross section $S_{r}\left(\mathrm{~m}^{2}\right)$ & $7.67 \times 10^{(-3)}$ \\
& Second moment of area of the rail cross-section & \\
& $I_{r}\left(\mathrm{~m}^{4}\right)$ & $3.0383 \times 10^{(-6)}$ \\
& Shear coefficient of the rail cross-section $k$ & 0.4 \\
Rail-pad & Vertical stiffness $K_{p}(\mathrm{MN} / \mathrm{m})$ & 350 \\
& Vertical damping $C_{p}(\mathrm{kN} . \mathrm{s} / \mathrm{m})$ & 50 \\
Sleeper & Mass of half sleeper $M_{s}(\mathrm{~kg})$ & 162 \\
& Spacing $l(\mathrm{~m})$ & 0.6 \\
Ballast & Vertical stiffness $K_{b}(\mathrm{MN} / \mathrm{m})$ & 50 \\
& Vertical damping $C_{b}(\mathrm{kN} . \mathrm{s} / \mathrm{m})$ & 100 \\
\hline
\end{tabular}


3.1 Generation of the random irregularity of track vertical profile

A theoretical random irregularity of the track vertical profile is introduced. Lei and Noda [12] suggested a power spectral density (PSD) of the rail irregularities based on the American Railway Standard, where $A_{v}$ and $\omega_{c}$ are coefficients related to the line grade and $\alpha$ is a constant generally taken as 0.25 :

$$
S(\omega)=\frac{\alpha A_{v} \omega_{c}}{\left(\omega^{2}+\omega_{c}^{2}\right) \omega}
$$

The sample of rail irregularities $\mathrm{r}(\mathrm{x})$ are then produced by Inverse Fourier transform. It is viewed as a stationary ergodic random process with a power spectral density $S(\omega)$ and expectation zero:

$$
r(x)=\sum_{i=1}^{N} \sqrt{4 S\left(\omega_{i}\right) \Delta \omega} \sin \left(\omega_{i} x+\varphi_{i}\right)
$$

The above power spectral density is defined in the frequency range $\left[\omega_{\min } ; \omega_{\max }\right]$ and is taken as zero outside these limits. $N$ is the chosen number of frequency increments. It allows to fix a frequency band $\Delta \omega$ and a circular frequency in the interval $\left[\omega_{\text {min }} ; \omega_{\text {max }}\right]$ given by:

$$
\begin{gathered}
\Delta \omega=\frac{\omega_{\text {max }}-\omega_{\text {min }}}{N} \\
\omega_{i}=\omega_{\text {min }}+\left(i-\frac{1}{2}\right) \Delta \omega, i=1,2, \ldots, N
\end{gathered}
$$

where $\varphi_{i}$ is a random phase uniformly distributed in $[0 ; 2 \pi]$.

\subsection{Mechanical model of the vehicle}

A quarter vehicle model of a BB26000 locomotive is described in Table 2 and Fig. 2. Indeed, the vehicle has geometrically two plans of symmetry $(x, z)$ and $(y, z)$. It consists of a multibody system where the car body is defined by a vertical motion $u_{c}$ and the bogie by a vertical and rolling motion $u_{b}$ and $\theta_{b}$.

Since the track's vibration is supposed negligible in front of the irregularity amplitude, the vehicle is expected to follow the track irregularity profile. In this way:

$$
\begin{gathered}
u_{w 1}(t)=r(V t) \\
u_{w 2}(t)=r(V t-d)
\end{gathered}
$$



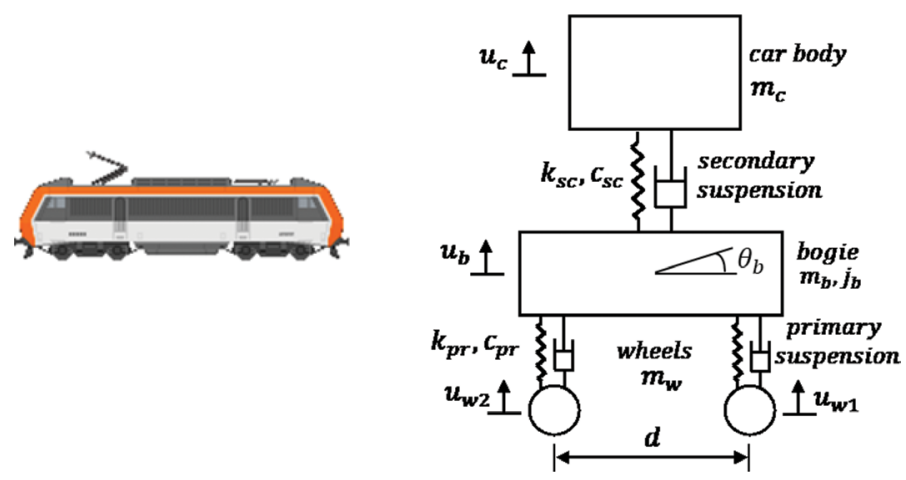

Figure 2: The BB26000 locomotive model.

Table 2: Vehicle characteristics.

\begin{tabular}{lll}
\hline Car body & Mass $M_{c}(\mathrm{~kg})$ & 46,800 \\
Secondary suspension & Stiffness $k_{s c}(\mathrm{MN} / \mathrm{m})$ & 1.23 \\
& Damping $c_{s c}(\mathrm{kN} . \mathrm{s} / \mathrm{m})$ & 20.54 \\
Bogie & Mass $M_{b}(\mathrm{~kg})$ & 13,485 \\
& Moment of inertia $J_{b}\left(\mathrm{~kg} \cdot \mathrm{m}^{2}\right)$ & $11,213.8$ \\
Primary suspension & Stiffness $k_{p r}(\mathrm{MN} / \mathrm{m})$ & 7.33 \\
& Damping $c_{p r}(\mathrm{kN} . \mathrm{s} / \mathrm{m})$ & 7.82 \\
Wheelset & Mass $M_{w}(\mathrm{~kg})$ & 3,805 \\
& Spacing $d(\mathrm{~m})$ & 2.8 \\
\hline
\end{tabular}

where $d$ is the wheelbase. Initially, the vehicle is in static equilibrium. The equations of motion of the system are then expressed by:

$$
\begin{gathered}
{\left[M_{v}\right]\{\dot{u}\}+\left[C_{v}\right]\{\dot{u}\}+\left[K_{v}\right]\{u\}=\{F\}} \\
\{u(t=0)\}=\left[K_{v}\right]^{-1}\{F(t=0)\} ;\{\dot{u}(t=0)\}=0
\end{gathered}
$$


The nodal displacement vector $\{u\}$ and the force vector are respectively expressed by:

$$
\begin{aligned}
& \{u\}=\left\{\begin{array}{l}
u_{c} \\
u_{b} \\
\theta_{b}
\end{array}\right\} \\
& \{F\}=\left\{\begin{array}{c}
-m_{c} g \\
-m_{b} g+c_{p r}\left(\dot{u}_{w 1}+\dot{u}_{w 2}\right)+k_{p r}\left(u_{w 1}+u_{w 2}\right) \\
-\left(\frac{d}{2}\right) c_{p r}\left(\dot{u}_{w 1}-\dot{u}_{w 2}\right)-\left(\frac{d}{2}\right) k_{p r}\left(u_{w 1}-u_{w 2}\right)
\end{array}\right\}
\end{aligned}
$$

The mass, damping and stiffness matrix are formulated below:

$$
\begin{aligned}
& {\left[M_{v}\right]=\left[\begin{array}{ccc}
m_{c} & 0 & 0 \\
0 & m_{b} & 0 \\
0 & 0 & j_{b}
\end{array}\right]} \\
& {\left[C_{v}\right]=\left[\begin{array}{ccc}
c_{s c} & -c_{s c} & 0 \\
-c_{s c} & \left(c_{s c}+2 c_{p r}\right) & 0 \\
0 & 0 & 2\left(\frac{d}{2}\right)^{2} c_{p r}
\end{array}\right],\left[k_{v}\right]=\left[\begin{array}{ccc}
k_{s c} & -k_{s c} & 0 \\
-k_{s c} & \left(k_{s c}+2 k_{p r}\right) & 0 \\
0 & 0 & 2\left(\frac{d}{2}\right)^{2} k_{p r}
\end{array}\right]}
\end{aligned}
$$

\section{VERTICAL TRACK RESPONSE TO A CONSTANT MOVING LOAD}

A first analysis aims to quantify track inertia's effect on its stress response. To this end, the above track model is subjected to a constant moving load and the dynamic response of the track is compared to its equivalent static response at each time step. 
The critical velocity of the track structure is at first determined and calculations are performed at lower speed for the moving load.

\subsection{Critical speed of the track structure}

When the load travels at the critical velocity of the track system, high deflections are generated. In order to predict this critical speed, the studied track model is approached by a continuous two-layer model. The rail is taken as an infinite Bernoulli beam characterised by its flexural stiffness $E I_{r}$ and its specific mass $m_{r}(\mathrm{~kg} / \mathrm{m})$. Rail-pads (first layer) are modelled as a continuous elastic layer having a stiffness $k_{1}\left(\mathrm{~N} / \mathrm{m}^{2}\right)=\frac{K_{p}}{l}$. The sleepers are modelled as a continuous layer having a mass per unit of length $m_{t}(\mathrm{~kg} / \mathrm{m})=\frac{M_{s}}{l}$. Finally, the ballast layer is also modelled as a continuous elastic layer having a stiffness $k_{2}\left(\mathrm{~N} / \mathrm{m}^{2}\right)=\frac{K_{b}}{l}$.

Equations of motion of both the rail and the sleeper layer are respectively written by:

$$
\begin{gathered}
E I_{r} \frac{\partial^{4} u_{r}}{\partial x^{4}}+m_{r} \frac{\partial^{2} u_{r}}{\partial t^{2}}+k_{1}\left(u_{r}-u_{t}\right)=f(x, t)=Q \delta(x-V t) \\
m_{t} \frac{\partial u_{t}}{\partial t}+k_{1}\left(u_{t}-u_{r}\right)+k_{2} u_{t}=0
\end{gathered}
$$

where $u_{r}$ and $u_{t}$ stand, respectively, for the vertical displacement of the rail and sleeper layer.

The harmonic solutions of the free wave propagation for $f(x, t)=0$ are given by:

$$
\begin{aligned}
& u_{r}=u_{r 0} e^{i \kappa(x-c t)} \\
& u_{t}=u_{t 0} e^{i \kappa(x-c t)}
\end{aligned}
$$

with $\kappa=\frac{2 \pi}{\lambda}$ is the wave number defined as a real quantity since there is no attenuation of the wave propagation and $c$ is the propagation velocity.

By injecting expressions (13) in the homogeneous form of eqn. (12) one obtains:

$$
\left[\begin{array}{cc}
E I_{r} \kappa^{4}+k_{1}-m_{r} c^{2} \kappa^{2} & -k_{1} \\
-k_{1} & -m_{t} c^{2} \kappa^{2}+k_{1}+k_{2}
\end{array}\right]\left\{\begin{array}{l}
u_{r 0} \\
u_{t 0}
\end{array}\right\}=\left\{\begin{array}{l}
0 \\
0
\end{array}\right\}
$$

The critical velocity can be determined as the propagation velocity that ensures the nullity of the determinant of the dynamic stiffness matrix [14,15] shown in (14). One obtains a biquadratic equation in $c$. Then, the critical velocity $V_{c}$ is obtained for the minimum positive root $c_{1}(\kappa)$ and a wave number $\kappa_{v}$ satisfying the condition $\frac{d c_{1}}{d \kappa}=0$ (i.e. $\left.c_{1}\left(\left|\kappa_{v}\right|\right)=c_{1, \min }\right)$. 
For the studied lightweight model, the theoretical critical speed reaches $V_{c} \approx 206 \mathrm{~m} / \mathrm{s}$. Simulation results at different moving load speeds $\left(0.25 V_{c}, 0.5 V_{c}, 2 V_{c}\right.$ and $\left.4 V_{c}\right)$ are presented in Fig. 3.

Given the same amplitude of the load, it clearly shows that for speeds below the critical speed, one obtains nearly the same stress response which is rapidly attenuated. However, above the critical speed, the stress profile becomes disturbed. Indeed, the solution tends to a harmonic response after the force reaches the beam's centre.

4.2 Vertical time response of the track in the rail mid-point

The following simulations are performed with a speed of $180 \mathrm{~km} / \mathrm{h}$.

\subsubsection{Moving load application methodology}

In the current model, the time step $d t$ and the mesh size $d x$ are chosen independently. They are taken respectively equal to $0.0002 \mathrm{~s}$ and $0.1 \mathrm{~m}$.

At each time step, the effective position of the load $Q$ is calculated given the speed and the time step. Thus, the load will be distributed among the two surrounding nodes $x_{i}$ and $x_{i+1}$ of the effective positive. Indeed, in the finite element theory, the structure is seen as a discretisation in a finite number of nodes.

4.2.2 Comparison of the dynamic and the static response of the track

The time evolution of dynamic bending and shear stress is computed at the mid-point of the rail for the moving load with an amplitude $Q \approx 110 \mathrm{kN}$ corresponding to the static wheel load of the BB26000 locomotive.
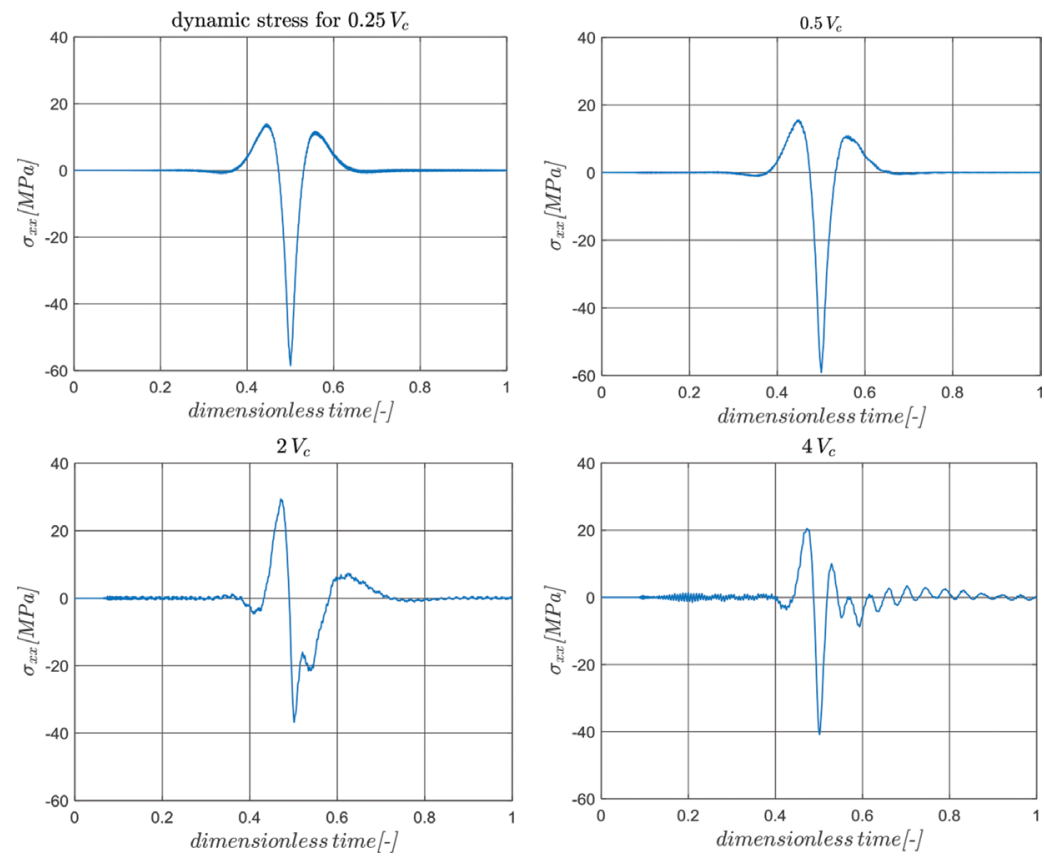

Figure 3: Effect of the moving load speed on the stress profile. 
The equivalent static response of the track is computed at each time step by way of the relation below:

$$
[K]\{u\}_{i}=\{Q\}_{i}
$$

In Fig. 4, two damping cases are considered: the reference damping from Table 1 and the case without track's damping. For both cases, the global shape of the dynamic response of the track is identical to the static one. Only vibrations with small amplitudes are added when damping is neglected. It could be explained by the fact that vertically, the track's stiffness is very high. Thus, fatigue analysis of the rail can be carried out considering the static response of the track to the moving load.

\section{EFFECT OF THE VEHICLE'S DYNAMIC ON THE TRACK RESPONSE}

In accordance to Section 3.1, a vertical random irregularity is generated in the mid-region of the track as shown in Fig. 5. It includes wave lengths $\lambda \in[3 m ; 9 m]$ to make sure that for a given time only one bogie is affected by the track's irregularity as the above vehicle's model includes only one bogie and the car body's rotation is neglected.

$A_{v}$ and $\omega_{c}$ are chosen respectively equal to $0.0339 \times 10^{-4} \mathrm{~m}^{2} / \mathrm{rd}$ and $0.8245 \mathrm{rd} / \mathrm{s}$. The number of frequency increments $N=2,000$.

On both sides of the mid-region, there is a progressive return to zero (i.e. track without defect) so that initially both vehicle's wheels are in the plane zone of the track.
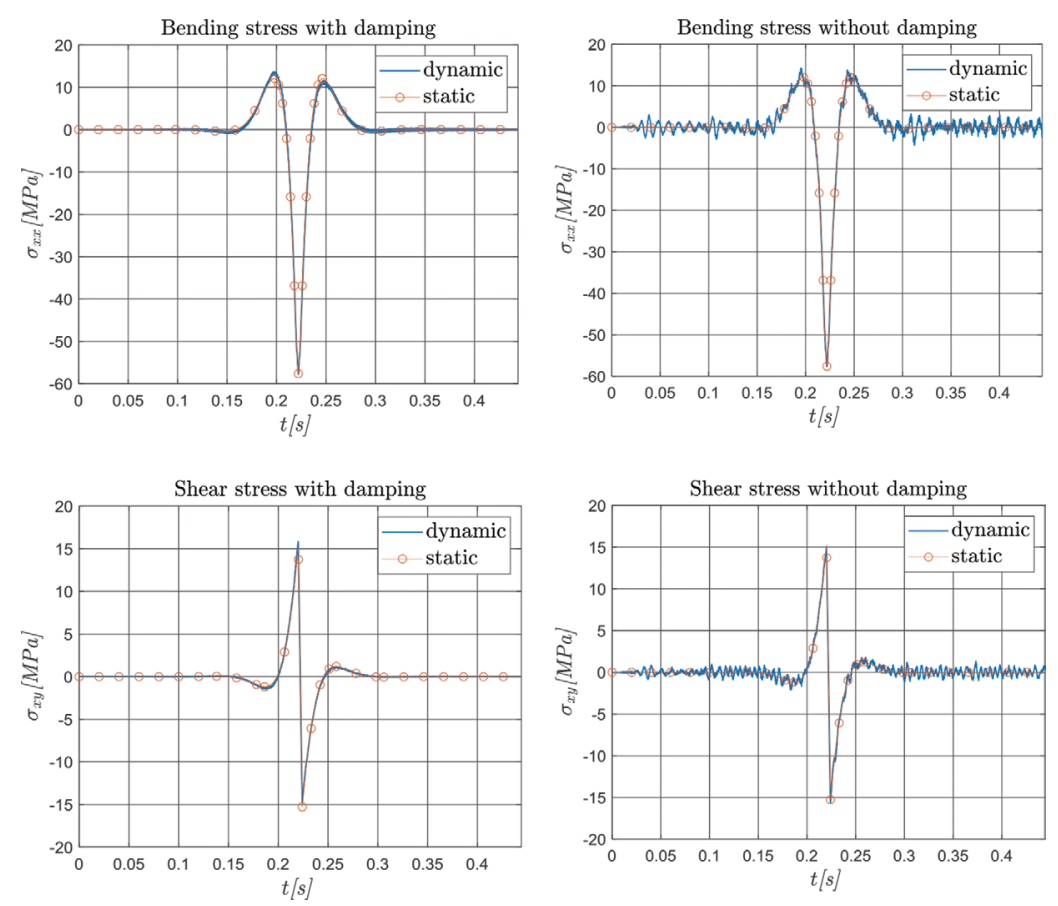

Figure 4: Comparison of static and dynamic stress response at the mid-point of the rail for a load speed $V=180 \mathrm{~km} / \mathrm{h}$. 

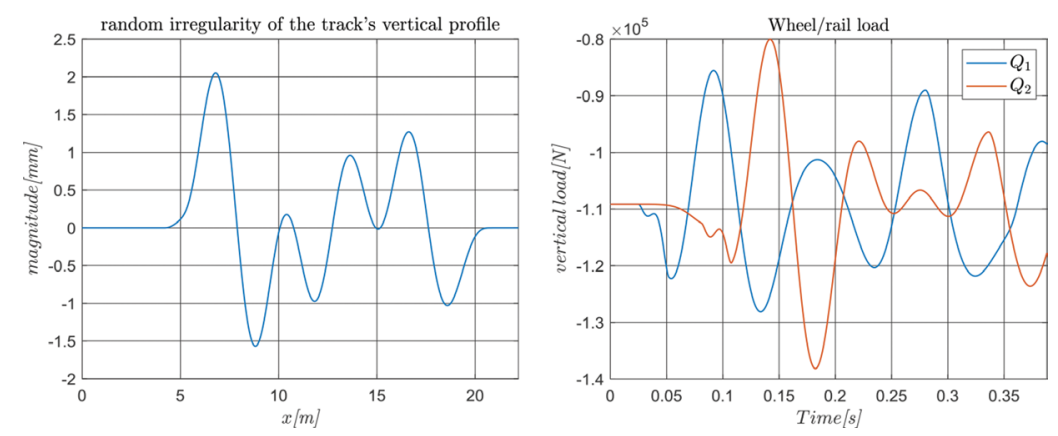

Figure 5: Random irregularity of the track's vertical profile and associated vehicle's dynamic loads for $V=180 \mathrm{~km} / \mathrm{h}$.

The maximum allowed speed for the BB 26000 locomotive $V=200 \mathrm{~km} / \mathrm{h}$ in accordance to manufacturer's data. A combination of the latter speed with the wavelengths' irregularity provides a frequency content of the wheel's excitation lower than $20 \mathrm{~Hz}$.

As the track is supposed infinitely rigid in this frequency range, only the track's geometry is supposed to affect the vehicle's dynamic. Hence, calculations are decoupled. Indeed, given the vertical profile of the track, the dynamic loads $Q_{1}(t)$ and $Q_{2}(t)$ exerted by the vehicle on the track at the level of each wheel are computed then implemented in the CAST3M track's model as two moving loads with variable amplitudes.

As it was noticed for the case of the moving load with a constant amplitude, the static and dynamic response of the track in term of stresses and vertical displacement are identical.

Fig. 6 shows the importance of considering dynamic overloads of the vehicle in the stress response of the track $\left(\sigma_{x x}, \sigma_{x y}\right)$. Indeed, an $L 2$ relative error norm $e$ is introduced in order to quantify the gap between the track's response $\left(\sigma_{1}\right)$ to constant amplitude loads being the static wheel loads and the track's response $\left(\sigma_{2}\right)$ to variable amplitude loads including dynamic overloads.

$$
e=\frac{\left[\sum_{i=1}^{N_{t}} \max _{j \in\left[1 ; N_{n}\right]}\left|\sigma_{1}\left(x_{j}, t_{i}\right)-\sigma_{2}\left(x_{j}, t_{i}\right)\right| \dagger\right]^{1 / 2}}{\left[\sum_{i=1}^{N_{t}}\left|\sigma_{1}\left(x_{j}, t_{i}\right)\right| \dagger\right]^{1 / 2}}
$$

where $N_{t}$ is the number of time increments and $N_{n}$ is the number of nodes contained in midregion of the rail.

Obviously, the error becomes more important when the speed increases. It reaches almost $18 \%$ for the bending and shear stress at $V=216 \mathrm{~km} / \mathrm{h}$. However, two local peaks are noticed approximately at $10 \mathrm{~km} / \mathrm{h}$ and $90 \mathrm{~km} / \mathrm{h}$. Indeed, for the latter speeds, the temporal spectral content of the track irregularity shows among others a frequency excitation that matches with a natural frequency of the vehicle system corresponding respectively to the bounce motion of the car body and the bounce motion of the bogie. 


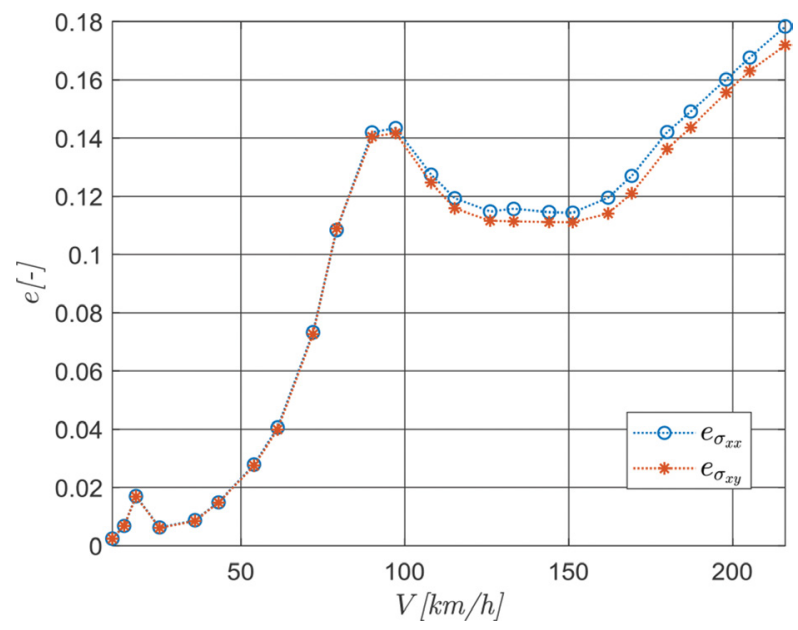

Figure 6: Speed impact on L2 relative error norm ( $e_{\sigma_{x x}}$ : error for bending stress; $e_{\sigma_{x y}}$ : error for shear stress)

\section{CONCLUSION}

A lightweight model of the track was presented in order to compute the stress response of the rail when the track is subjected to moving loads. A first investigation when considering constant amplitudes of moving loads showed that the vertical dynamic response of the track was identical to the static one, certainly due to the high stiffness of the track in the vertical direction. An additional study aimed to quantify the effect of a vehicle's dynamic overloads on the track response. It showed that the stress amplitude in the rail was considerably affected by these overloads, especially for higher speeds. Hence, vertically, the prediction of mechanical stress state in the rail for fatigue issues is achieved through a static track model and a simplified dynamic model for the vehicle.

Further investigations are intended in order to characterise the lateral behaviour of the track. Unlike the vertical direction, track's dynamic for the lateral response is expected to be significant as the track is more flexible, and less way damped than in the vertical direction.

\section{REFERENCES}

[1] Commission de circulation des machines (SNCF), Rapport de la commission Demaux, 1944.

[2] SNCF, Règles d'admission des matériels roulants sur le RFN en fonction de la sollicitation de la voie, RFN-IG-MR 00 A-00-n 001, 2013.

[3] Guerin, N., Approche expérimentale et numérique du comportement du ballast des voies ferrées. PHD. Matériaux. Ecole Nationale des Ponts et Chaussées, 1996.

[4] Nguyen, V.H., Comportement dynamique de structures non-linéaires soumises à des charges mobiles. PHD. Ecole Nationale des Ponts et Chaussées, 2002.

[5] Al Shaer, A., Analyse des déformations permanentes des voies ferrées ballastéesApproche dynamique. PHD. ENPC, 2005.

[6] Sayeed, M. A. \& Shahin, M. A., Three-dimensional numerical modelling of ballasted railway track foundations for high-speed trains with special reference to critical speed. Transportation Geotechnics, 6, pp. 55-65, 2016. 
[7] Fernandes, V.A., Numerical analysis of nonlinear soil behavior and heterogeneity effects on railway track response. PHD. Ecole Centrale Paris, 2014.

[8] Rhayma, N., Contribution à l'évolution des méthodologies de caractérisation et d'amélioration des voies ferrées. PHD. Université Blaise Pascal - Clermont-Ferrand II, 2010.

[9] http://www-cast3m.cea.fr

[10] Xie, G. \& Iwnicki, S. D., Simulation of wear on a rough rail using a time-domain wheel-track interaction model. Wear, 265(11-12), pp. 1572-1583, 2008.

[11] Knothe, K. L. \& Grassie, S. L., Modelling of railway track and vehicle/track interaction at high frequencies. Vehicle system dynamics, 22(3-4), pp. 209-262, 1993.

[12] Lei, X. \& Noda, N. A., Analyses of dynamic response of vehicle and track coupling system with random irregularity of track vertical profile. Journal of Sound and Vibration, 258(1), pp. 147-165, 2002.

[13] Newmark, N. M., A method of computation for structural dynamics. Journal of the Engineering Mechanics Division, Proceeding of American Society of Civil Engineers, pp. 67-94, 1959.

[14] Chen, Y. H., Huang, Y. H. \& Shih, C.T., Response of an infinite Timoshenko beam on a viscoelastic foundation to a harmonic moving load. Journal of sound and Vibration, 241(5), pp. 809-824, 2001.

[15] Stojanović, V., Kozić, P. \& Petković, M. D., Dynamic instability and critical velocity of a mass moving uniformly along a stabilized infinity beam. International Journal of Solids and Structures, 108, pp. 164-174, 2017. 